\title{
RE-INTRODUCTION OF GLOBALLY THREATENED ARABIAN GAZELLES GAZELla ARABICA (PALLAS, 1766) (MAMMALIA: BOVIDAE) IN FENCED PROTECTED AREA IN CENTRAL SAUdi ARABIA
}

\author{
M. Zafar-ul Islam ${ }^{1}$, Moayyad Sher Shah ${ }^{2} \&$ Ahmed Boug $^{3}$ \\ 1,2,3 National Wildlife Research Center, PO Box 1086, Taif, Saudi Arabia AND Saudi Wildlife Authority, PO Box 61681 , \\ Riyadh 11575, Saudi Arabia \\ ${ }^{1}$ mzafarul.islam@gmail.com (corresponding author)
}

Abstract: The Arabian Gazelle is a globally threatened antelope (Vulnerable) in Saudi Arabia. Small relict populations remain in limited areas, while historically Arabian gazelles occurred in Mahazat as-Sayd protected area in central Saudi Arabia but were exterminated by anthropogenic and other pressures, including habitat loss and hunting. Important habitat has been lost to agricultural developments, fencing of pasture for livestock and the construction of human settlements and roads. The reintroduction of Arabian Gazelles was undertaken in Mahazat during 2011-2014 to bring back this locally extinct species study its ecology and biology in a fenced protected area. We released a total of 49 (12 males, 37 females) animals. A year after release animals started breeding and six calves have been recorded so far with more to come. The gazelles prefer to use more rocky areas where shrubs and acacia trees occur in the reserve, and do not move long distances except for one individual that moved more than $50 \mathrm{~km}$. Mahazat is fenced, which prevents local people from entering the reserve to poach or otherwise disturb animals. Management lessons include the need for continued monitoring of reintroduced populations. Interactions between Arabian and Sand Gazelles (Gazella subgutturosa marica) and Arabian Oryx (Oryx leucoryx) were also studied.

Keywords: Arabia, gazelles, management, reintroduction, threatened.

DOI: http://dx.doi.org/10.11609/JoTT.03971.6053-60 | ZooBank: urn:Isid:zoobank.org:pub:631E39DC-623C-4B68-A94C-04DE65C3D46E

Editor: David Mallon, Zoological Society of London, UK.

Date of publication: 26 July 2014 (online \& print)

Manuscript details: Ms \# 03971 | Received 16 March 2014 | Final received 05 May 2014 | Finally accepted 24 June 2014

Citation: Islam, M.Z., M.S. Shah \& A. Boug (2014). Re-introduction of globally threatened Arabian Gazelles Gazella arabica (Pallas, 1766) (Mammalia: Bovidae) in fenced protected area in central Saudi Arabia. Journal of Threatened Taxa 6(8): 6053-6060; http://dx.doi.org/10.11609/JoTT.03971.6053-60

Copyright: (C) Islam 2014. Creative Commons Attribution 4.0 International License. JoTT allows unrestricted use of this article in any medium, reproduction and distribution by providing adequate credit to the authors and the source of publication.

Funding: The Project is funded by the Saudi Wildlife Authority, Riyadh Saudi Arabia.

Competing Interest: The authors declare no competing interests.

Author Contribution: All authors have been involved in designing and making the project proposal till reintroduction and animals monitoring in Mahazat.

Author Details: DR. M. ZAFAR-UL ISLAM is Research Director and field biologist with strong interest in international wildlife conservation and had been associated with BirdLife International (UK), RSPB (UK), BNHS (India) and Aligarh Muslim University (India). His main research work is on ecology and biology of threatened taxa with their habitat evaluation and niche modelling. Since April 2006, he is looking after the re-introduction and other field research programs of the country with the National Wildlife Research Center in Taif, Saudi Arabia. MR. MOAYYAD SHER SHA. is field researcher working in Mahazat as-Sayd protected area in Saudi Arabia since last 14 years on Houbara Bustard and also worked on Arabian and Sand gazelles, and Sand Cat. MR. AHMED Boug is General Director of National Wildlife Research Center and field biologist who studied the ecology and biology of Hamadrays Baboon in Saudi Arabia. He has produced several papers in international journals on his research.

Acknowledgements: We want to extend our thanks and gratitude to HH Prince Bander Bin Saud Bin Mohammed Al Saud (President, Saudi Wildlife Authority) for his leadership, generosity and continuous support towards the research and conservation work by the NWRC in the Kingdom. All NWRC/KKWRC staffs are acknowledged for their help, especially Dr. Mohammed Sandouka, Raziman Khan, Mr. Sham Davande for help in mapping and Ms. Parveen Khan (Librarian) for providing papers and literature during writing this paper. We want to thank Dr. David Mallon for reviewing this paper. 


\section{INTRODUCTION}

The taxonomy of gazelles is notoriously complex, and several classifications have been proposed. Three species have been reported from Saudi Arabia: Saudi Gazelle Gazella saudiya (now extinct), Mountain Gazelle Gazella gazella (widespread in the Arabian Peninsula) and Arabian Gazelle Gazella arabica (known only from a specimen collected in the 1820s on the Farasan Islands in the Red Sea). Recent genetic research has questioned this arrangement. Lerp et al. (2013) indicated that $G$. gazella in fact consists of two clades, one in the north centred on the Golan Heights, and a southern clade covering the rest of the former range. Bärmann et al. (2012) demonstrated that $G$. arabica had been misidentified and the specimen was in fact G. gazella. These authors, therefore, proposed a nomenclatural change, preferring to use the name G. arabica for the southern clade of G. gazella. This arrangement is followed here for gazelles in Saudi Arabia, including the former subspecies G.g. cora and G.g. farasani (Thouless \& Bassri 1991; Groves 1997; Flammand et al. 1998; Grubb 2005).

The former range of $G$. gazella included southern Turkey, Israel, Iran (Farur Island), Oman, United Arab Emirates, Yemen and Saudi Arabia (Mallon \& Kingswood 2001; Kankýlýç et al. 2012). Occasional sightings have been reported from Egypt (Sinai), Syria, Lebanon and Jordan (Kingswood \& Khairallah 2001; Saleh 2001; Masseti 2004). The range of $G$. g. cora (here referred to as the Arabian Gazelle G. arabica) occurred across most of the Arabian Peninsula from the Arava Valley in southern Israel, along the Hejaz and Asir Mountains in western Saudi Arabia (12-28 $\left.{ }^{\circ} \mathrm{N}\right)$, through Yemen, Oman and into the Emirates (Shalmon 1987; Uerpmann 1987; Dunham et al. 2001; Insall 2001; Mallon \& Al-Safadi 2001; Samour 2001).

In Saudi Arabia, Arabian Gazelle numbers have decreased dramatically throughout their range since the middle of the $20^{\text {th }}$ century due to anthropogenic and other pressures including habitat loss and hunting. Important habitat has been lost to agricultural developments, fencing of pasture for livestock and the construction of human settlements and roads (Habibi 1986; Nader 1989; Thouless et al. 1991; Islam et al. 2010a,b). The IUCN Red List (IUCN 2009, 2014) currently ranks this species (as G. gazella) as 'Vulnerable' (A2ad). Small relict populations may still occur in Al Khunfah and Harrat al Harrah in the north of Saudi Arabia (Harrison 1968; Green 1986; Thouless et al. 1991; Habibi 1992; Wacher 1993; Seddon et al. 1997; Islam et al. 2012) and on the Tihama coastal plain (Thouless et al. 1991, 1997; Magin 1993, 1996; Wacher \& AlAgeel 2001a; Ahmed Boug pers. comm. March 1999, in Wadi Hali; Zafar-ul Islam pers. obs. 22 February 2009, 80km south of Al Qunfidah). On the Farasan Islands a strong population of about 1000 individuals has survived (Flammand et al. 1998; Cunningham \& Wronski 2010), and Arabian Gazelles were released in two protected areas (Ibex Reserve, Uruq Bani Ma'Arid) from 1990 to 2007 (Islam et al. 2012; Wronski et al. 2012a,b,c). Most records of natural Arabian gazelle populations in Saudi Arabia originate from the western part of the Kingdom, i.e., the Asir, Sarawat and Hejaz Mountains (Thouless et al. 1991, 1997; Magin 1993, 1996; Al-Hazmi \& Ghandour 1992; Magin \& Greth 1994). Four populations are known from the northern Hejaz Mountains extending from Medina up towards the Gulf of Aqaba, namely Jibal Kallab, Harrat Uwayrid, Ras Suwaihil and Jibal Dakhkhan (Child \& Grainger 1990; Thouless et al. 1991, 1997; Wacher \& AlAgeel 1999; Wacher \& Strauss 2000; Wacher 2001; Ahmed Boug pers. comm. March 1999, near Al Farah). The Hejaz Mountains are more arid than the southern Asir and Sarawat Mountains where permanent water is available throughout the year. In the Asir and Sarawat Mountains a number of gazelle populations were reported to survive in the foothills and in the eastern flanks of the Asir, where they are mostly associated with Acacia-lined wadis (Thouless et al. 1991). From 19902001, several surveys have focused on a number of populations in the Asir National Park (Al Khalili \& Nader 1984; M.Z. Islam pers. comm. 2013) and other proposed protected areas in the region to confirm presence or absence of gazelles or to establish rough population estimates (Child \& Grainger 1990; Magin 1993, 1996; Thouless et al. 1997; Wacher \& Al Toum 1998; Wacher \& AlAgeel 2001b). Since 2001 no confirmed observations of Arabian Gazelles in the Asir Mountains have been reported. Three observations were made by a local shepherd near Jabal Kabkab in Makkah in January 2014 (A. Boug and wildlife rangers pers. comm. 2014).

Historically, Arabian Gazelles occured in Mahazat as-Sayd Protected Area in central Saudi Arabia but their loss was attributed to anthropogenic and other pressures (Child \& Grainger 1990; Lewlin in press, Islam et al. 2010a,b). Since their presence was confirmed via interviews with local people and historical records (Magin 1996; Thouless et al. 1997; Islam et al. 2010a,b), the Strategy and Action Plan of the National Wildlife Research Center (NWRC) suggested the re-introduction of Arabian Gazelles (Islam et al. 2010a,b). This project is particularly significant as it is one of the first successful 
releases for the species in over 20 years (Islam et al. 2011, 2012). After many years of dedicated work to identify and conserve different species of gazelles in Saudi Arabia, these elegant gazelles were successfully released. The release is part of the ongoing efforts in the Kingdom to conserve a variety of antelopes, an initiative that is strongly supported by the Saudi people (Magin 1996; Thouless et al. 1997; Islam et al. 2010a,b).

The need to reintroduce gazelles from captive bred populations was identified at an early stage by the Saudi Wildlife Authority and endorsed by an International Conference on Conservation of Arabian Gazelles (Greth et al. 1996). In line with conference recommendations, the IUCN guidelines for reintroduction were followed (IUCN 1998). Key subsidiary recommendations in this approach to reintroduction are that only appropriate taxa are released within their former historic range and that the original cause of extinction has been identified and controlled or eliminated. Gazelles reintroduced have all been placed into former range areas in fenced protected area. Extensive taxonomic research, including molecular genetic research, has been undertaken to ensure accurate identification in this difficult group (Greth et al. 1996; Hammond et al. 2001).

The reintroduction of the Arabian Gazelles was undertaking with the following goals: (a) to re-establish wild and self-sustaining populations of Arabian Gazelle in Saudi Arabia; (b) to study the most suitable habitats and establish protected areas in which vegetation can recover; (c) to manage the re-introduction of herds in protected areas; (d) to re-introduce in suitable habitats; and (e) to study the ecology and biology of gazelles in the protected area.

\section{STUDY AREA}

The Mahazat as-Sayd Protected Area $\left(22^{\circ} 15^{\prime} \mathrm{N}-41^{\circ} 40^{\prime} \mathrm{E}\right)$ is located in west-central Saudi Arabia and consists of a gently undulating sand and gravel plain at about $900 \mathrm{~m}$ altitude comprising dwarfscrubland dominated by Acacia tortilis trees, other Acacia ehrenbergiana as well as Maerua crassifolia trees (Fisher \& Membery 1998). Perennial grasses, such as Panicum turgidum, Lasiurus scindicus and Octhochloa ompressa, which are important Arabian Gazelle forage species (Blank 2000; Shah et al. 2013), are abundant on sandy areas and some of elevated areas and depressions. Net primary production in Mahazat asSayd is low and rainfall is unpredictable and patchily distributed (Treydte et al. 2001). Mean temperature ranges from $17^{\circ} \mathrm{C}$ in winter to $34^{\circ} \mathrm{C}$ in summer, but maximum temperatures in summer often exceed $45^{\circ} \mathrm{C}$ (Islam et al. 2012). Mahazat as-Sayd is completely fenced $\left(2244 \mathrm{~km}^{2}\right)$ and was gazetted in 1988 as a reintroduction site for Arabian Oryx (Oryx leucoryx), Houbara Bustard (Chlamydotis macqueenii) and the Arabian Sand Gazelle (Gazella subgutturosa marica) and Arabian Gazelle (Vessey-Fitzgerald 1952; Child \& Grainger 1990; Islam et al. 2012). Predators were originally eradicated from several protected areas, but one Arabian Wolf (Canis lupus) was located in Mahazat in 2008 (Musleh Ammar (Head ranger) pers. comm. 2012). The Arabian Gazelles were originally extirpated primarily by excessive hunting before declaration of PA (Islam et al. 2010a,b).

After the identification the area as wildlife reserve with fencing and proper protection from livestock grazing, within five years the recovery of the vegetation increased the chances of re-introduction of Arabian Gazelles in the area as compared to areas outside the reserve, which was overgrazed and disturbed. The local community was taken in to confidence during the process and Saudi Wildlife Authority got full support both from civil society and the government for the reintroduction of native wildlife.

\section{METHODS}

Arabian Gazelles were captured just before dark by using boma-trapping and put in individual crates constructed of plywood and measuring 100x36x90 $\mathrm{cm}$. Crates could be opened from both ends and had 30-40 ventilation holes of $1 \mathrm{~cm}$ diameter. Animals were transported the $670 \mathrm{~km}$ to Mahazat at night by truck. Upon arrival at the reserve the gazelles were placed in a quarantine enclosures identical in size $(500 \times 500 \mathrm{~m})$ and features to those at the KKWRC. Food and water were provided in enclosure. Arabian Gazelles were obtained from King Khalid Wildlife Research Center (KKWRC). All the translocated gazelles were born in captivity at KKWRC.

Between 2011 and 2014, three groups of animals were released from the pre-release enclosure into wild when the vegetation condition was favorable. All animals were released by opening gates of pre-release enclosure and allowing them to leave of their own, while water and alfalfa was provided outside of the enclosure for three weeks. All animals that were radio-tagged were monitored on a daily basis by ground telemetry and at least once a fortnight by aerial telemetry using Maule aircraft and date, time, location, activity, habitat 


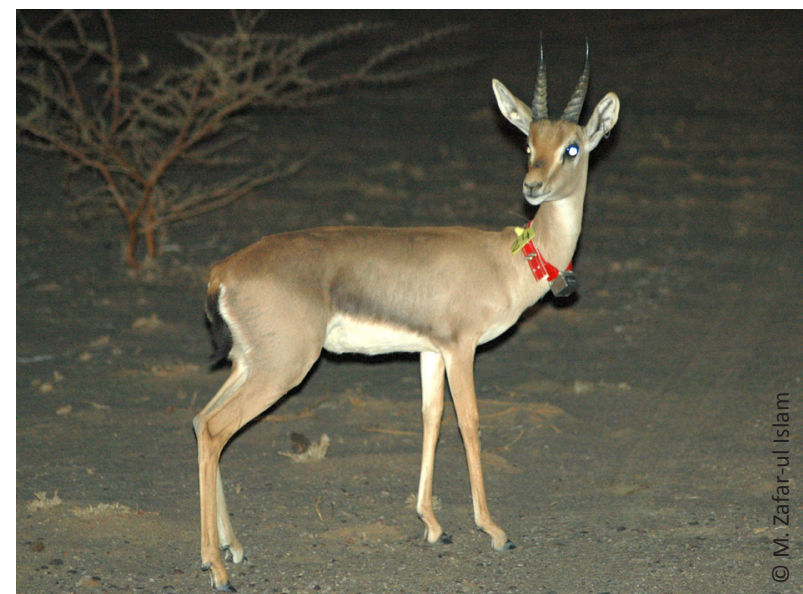

Image 1. Arabian Mountain Gazelle male in the night

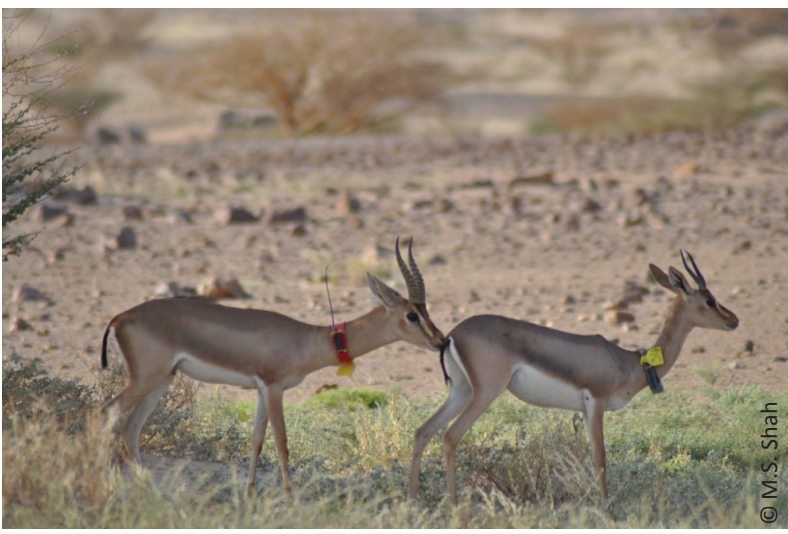

Image 3. Arabian Mountain Gazelle male with collars

and group compositions were recorded.

First Release: The first group of 17 (4 males, 13 females) Arabian Gazelles was transferred from KKWRC to Mahazat on 14 March 2011 by road. Age of gazelles ranged between three months old calf to 10 years old. Radio-collars were secured to each individual with tag numbers. One female died on 19 March 2011 in the release pen. On 08 April 2011 four Arabian Gazelles (1 male, 3 females) were released directly from boxes by His Highness Prince Bandar bin Saud bin Mohammed Al Saud (President of SWA), including two (1 male, 1 female) from NWRC and other two females from KKWRC. The remaining 14 gazelles (4 males, 10 females) were kept in the pre-release enclosure and released by opening the gate (Images 1-4).

Second Release: The second group of 23 (8 males, 15 females) gazelles was transferred from KKWRC to Mahazat on 12 February 2012. Age structure of this group was mostly 2-4 years old and ranged between $1-5$ years old animals. One female gazelle was recorded

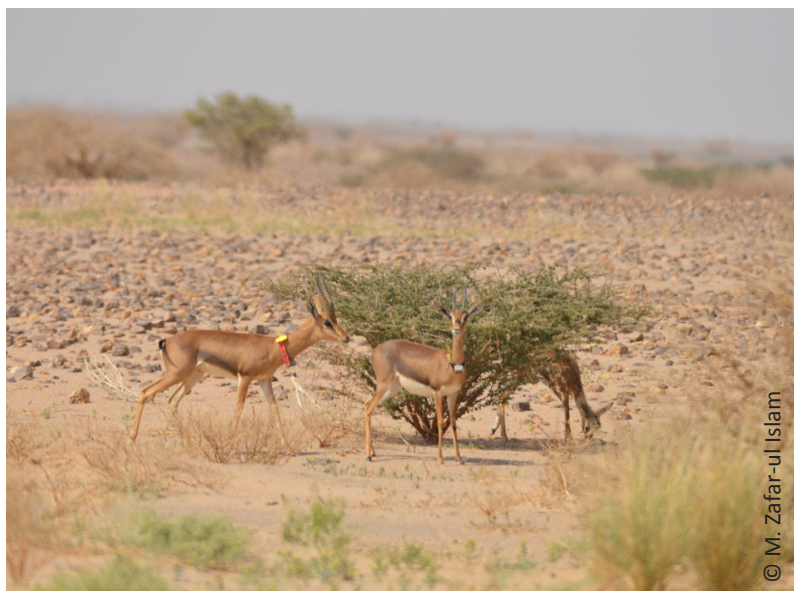

Image 2. Arabian Mountain Gazelles with collars males and a female

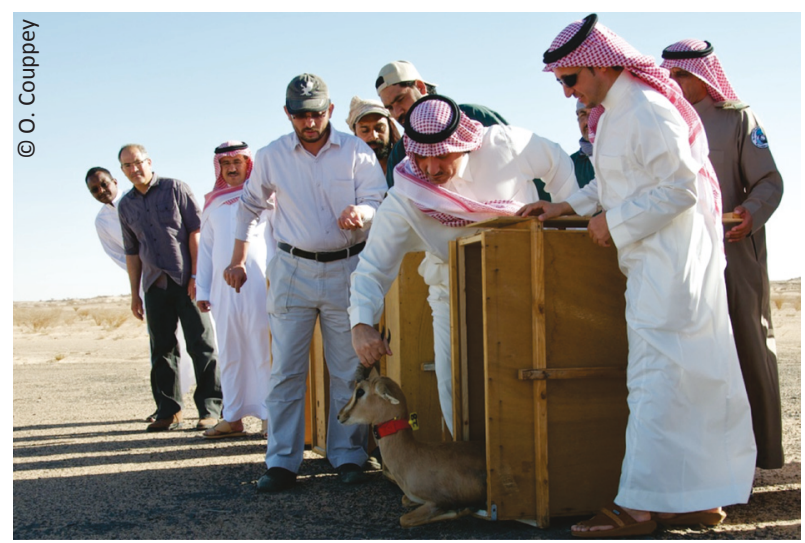

Image 4. Arabian Mountain Gazelle released by HH Prince Bander (President of SWA)

dead in the pre-release enclosure on 21 February 2012. This group of 22 Arabian Gazelles was released by opening the enclosure gate on 06 March 2012.

Third release: Another nine animals ( 2 males; 7 females) were released in Mahazat in June 2014.

All animals were tested for tuberculosis, vaccinated against rabies, foot and mouth disease, rinderpest, and pasteurellosis, marked with either eartags, marker collars, or radio transmitters, and placed in quarantine pens for a few months and soft released by opening the gate of the enclosure.

\section{RESULTS}

Post-release monitoring: In summer of 2011 and 2014, when the vegetation mostly dried off, a total of eight Arabian Gazelles were recorded dead, mostly just after the release from the first release between 


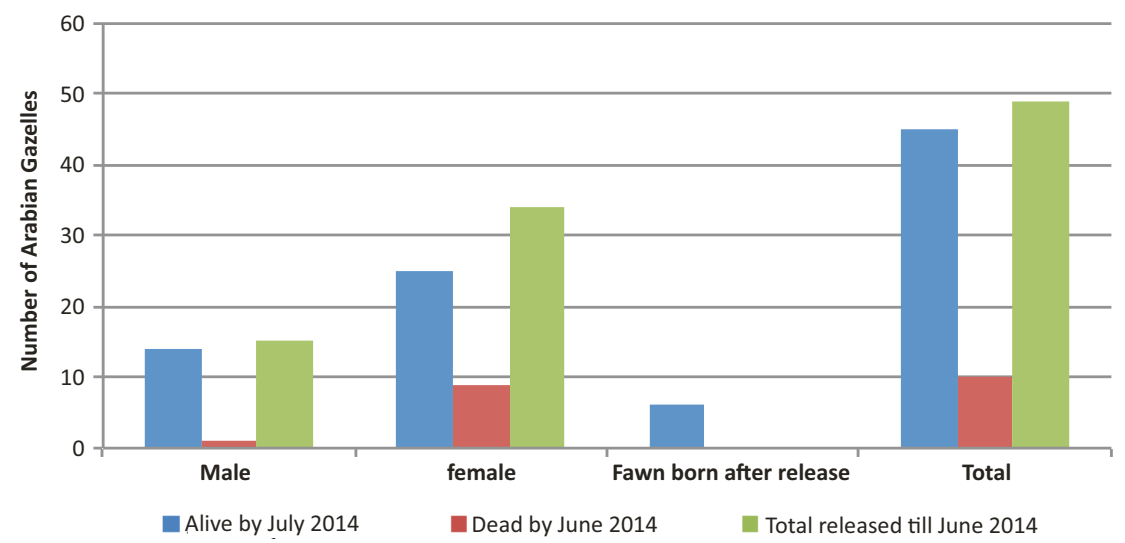

Figure 1. Status of re-introduced Arabian Gazelles in Mahazat PA with fawn born in the wild

May and November 2011 and five gazelles (1 male, 4 females) went missing due to radio-collar failure and the radio collar fell off one female. These animals were not recorded again until now. Only one female was found dead on 13 March 2012 among the second released group. Mortalities were controlled by further improving the release method by releasing animals in winter months, not as late as in 2011. Another factor assisting the successful release was that the reserve received good rainfall contributing to the growth of greenery.

Post-release dispersal of Arabian Gazelles has been recorded from the intensive monitoring programmes. After release, the productivity was high. After one year of release, the gazelles started breeding and five radiotagged females gave birth to calves (Fig. 1).

Breeding records of the gazelles: The first wild born Arabian Gazelles calf was recorded in Mahazat on 28 August 2012 near the fence. This calf was almost one month old when recorded with the group. Six other females delivered one each by end of September 2012. The offspring show more adaptability to the wild than their captive-bred parents. All young animals born before the end of 2012 were alive at the end of 2013 . The present population of Arabian Gazelle in Mahazat reserve is $40-50$ (Fig. 1 ).

Studies related to habitat use, feeding ecology, range and space use, and group composition are being carried out in Mahazat.

\section{Habitat preference by Arabian Gazelles}

A recent spot image with $2.5 \mathrm{~m}$ resolution in color was acquired from the remote sensing section of the King Abduaziz City for Science and Technology in Saudi Arabia for the Mahazat as-Sayd Protected Area to study the landcover and classified in four major classes. The dominant landcover class is sandy followed by rocky
Table 1. Landcover classfication of satellite image and habitat use by gazelles

\begin{tabular}{|c|l|c|c|c|}
\hline & $\begin{array}{l}\text { Landcover } \\
\text { class }\end{array}$ & $\begin{array}{c}\text { Area in } \\
\text { sqkm }\end{array}$ & $\begin{array}{c}\text { Percent } \\
\text { Area }\end{array}$ & $\begin{array}{c}\text { Percent Area used by } \\
\text { Arabian Gazelle } \\
\text { (landcover) }\end{array}$ \\
\hline 1 & Sandy areas & 1014 & 45 & 08 \\
\hline 2 & Rocky barren & 478 & 21 & 43 \\
\hline 3 & Grasslands & 432 & 19 & 34 \\
\hline 4 & Scrub forest & 320 & 14 & 17 \\
\hline Total & & 2244 & 100 & 100 \\
\hline
\end{tabular}

and grassland as depicted in Table 1 and Fig. 2. Arabian Gazlles use mainly scrub and grassland areas in the rocky barren and most avoiding sandy areas in the reserves (Fig. 2).

Food and water: The released gazelles and their offspring were mixed feeders, eating grasses, forbs, and shrubs. Growing leaves of Acacia tortilis were eaten. Occasionally gazelles were observed to stand on their hind legs, resting the forelegs on bush, to reach leaves growing above their normal levels.

After release, gazelles were occasionally seen drinking water from the waterhole that was created especially for them. Once animals moved away from the release sites, the territorial male was rarely seen outside his territory; however, regular checks were made for the gazelle footprints near the release site and some of the animals used to visit in the late evening and early morning in search of food and water.

One of the males moved almost $20 \mathrm{~km}$ from the release sites. The release site is near to the hilly part of the reserve $(10 \mathrm{~km}$ away) and most of the animals are confined to these areas. Females who were about to deliver young went to a secluded place and after delivering the calf, female and the calf moved around 

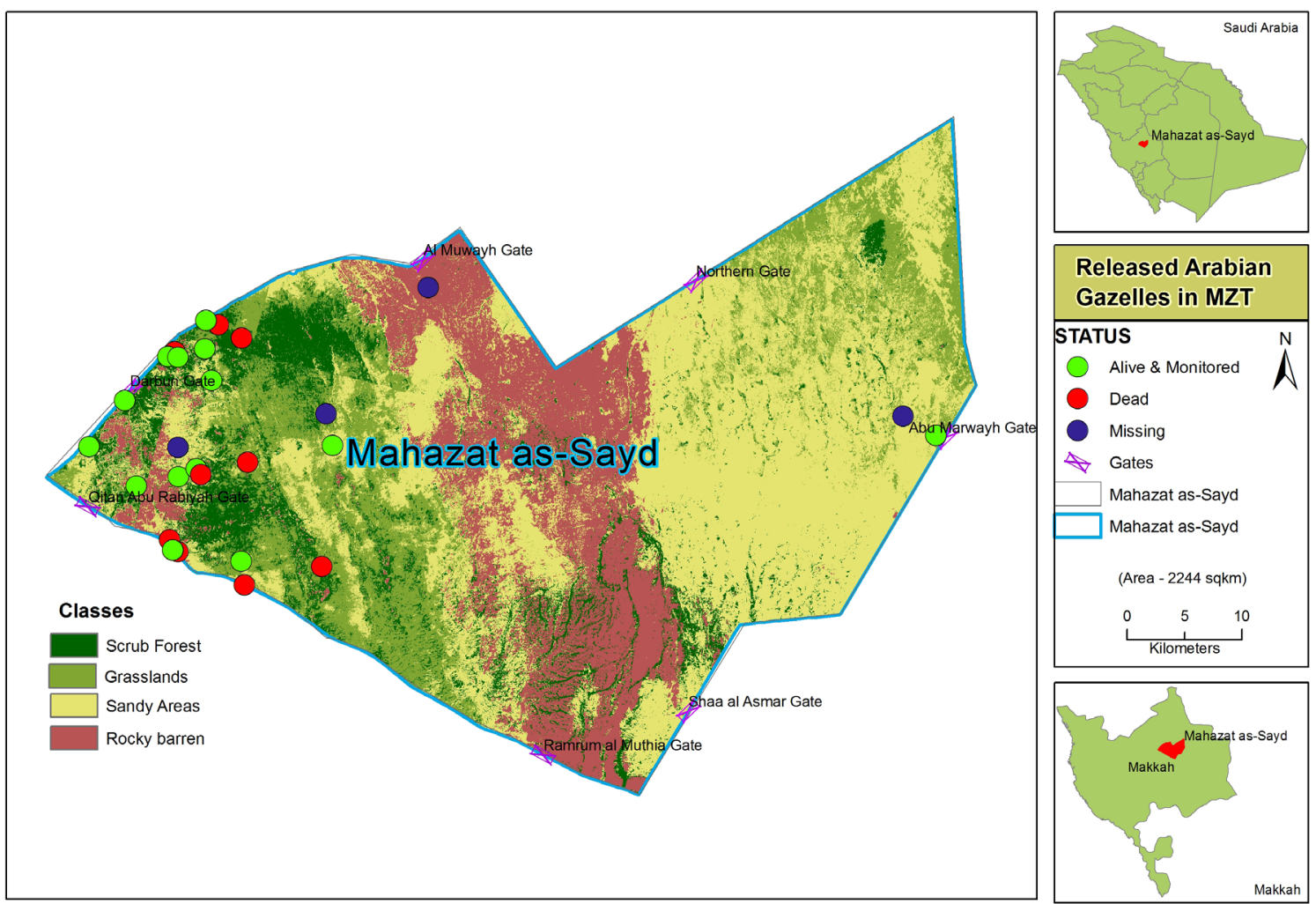

Figure 2. Land-use pattern and distribution of Arabian Gazelles in Mahazat PA.

$50 \mathrm{~m}$ away, likely to avoid small carnivores being attracted to the smell of the placenta.

\section{DISCUSSION}

The reintroduction of the Arabian Gazelles in Mahazat as-Sayd has faced some difficulties including (a) maintaining long-term regular monitoring due to lack of full time researchers; (b) lack of skills for mass capture techniques for Arabian Gazelles in case of need to fix or re-fix the radio collars, especially of new born individuals.

Major lessons learned from other reintroductions in Saudi Arabia include (a) when wide-ranging species are confined to restricted areas, even if such areas are large, it is essential that an effective population management plan is in place before any re-introduction is carried out, and that the plan is properly implemented. If this is not done, large-scale mortalities will occur (Islam et al. 2010a,b); (b) prior to any transplantation, range conditions in the release area have to be improved and the area protected from livestock exploitation. Once pasture conditions show adequate signs of improvement and the site is adequately protected, re-introduction of the animals can be contemplated; (c) the time of release should coincide with suitable vegetation conditions; (d) keeping the animals in pre-release enclosures within the re-introduction site to get them acclimatized to the natural environment and provide minimal amount of food and water; (e) regulate tourism in re-introduction areas as this can lead to increased habitat degradation; and $(f)$ a public-awareness program should be put in place to inform citizens of the biological and historic significance of the Sand Gazelle in the society.

A healthy (disease-free, injury-free) breeding Arabian Gazelle population has been established in Mahazat asSayd Protected Area for more than two years, and is considered to be a success. Productivity by released Arabian Gazelles high; society and the government support the re-introduction and Mahazat has been suggested as a destination for national and international tourists.

\section{Management plan}

The ungulate populations in the Mahazat As-Sayd Protected Area are valuable resources that could be put to good conservation (or other use) with careful planning. An active management plan for the ungulate populations in Mahazat As-Sayd Protected Area was 
developed in the end of 2008 by experts including ecologists, biologists, botanists, vets, sociologists and policy and decision makers to minimize periodic largescale mortalities in the reserve (Islam et al. 2010b).

In the plan artificial provision of water and alfalfa is provided at five different locations to animals in Mahazat since May 2008 to minimize mortality.

Under this project, auxiliary rangers are given training to monitor the population and protect it from suspected hunters. Such surveillance would be greatly facilitated by the rugged nature of most gazelles in the area.

\section{REFERENCES}

Al-Khalili, A.D. \& I.A. Nader (1984). Nature conservation in Saud Arabia. An ecological study of the Asir National Park with check-list of the terrestrial vertebrate fauna of the park and its surrounding. Fauna of Saudi Arabia 6: 11-31.

Al-Hazmi, M.A. \& A.M. Ghandour (1992). An ecological study of gazelles in the western and southern regions of Saudi Arabia. Journal of Arid Environments 23: 279-286.

Bärmann, E.V., S. Börner, D. Erpenbeck, G.E. Rössner, C. Hebe \& G. Wörheide (2012). The curious case of Gazella arabica. Mammalian Biology 78: 220-225; http://dx.doi.org/10.1016/j. mambio.2012.07.003

Blank, D.A. (2000). Acacia gazelle increases with habitat improvement. Gnusletter 19(1): 11-13.

Child, G. \& J. Grainger (1990). A system plan for protected areas for wildlife conservation and sustainable rural development. Nationa Commission for Wildlife Conservation and Development, Riyadh.

Cunningham, P.L. \& T. Wronski (2010). Twenty years of gazelle monitoring on Farasan Islands: An overview. Oryx 45(1): 50-55; http://dx.doi.org/10.1017/S0030605310001298

Cunningham, P.L., T. Wronski \& K. Al Aqeel (2010). Predators persecuted in the Asir Region, western Saudi Arabia. Wildlife Middle East News 4(1): 6

Dunham, K.M., D.T. Williamson \& E. Joubert (2001). Saudi Arabia, pp. 55-62. In: Mallon, D.P. \& S.C. Kingswood (eds). Antelopes, Part 4: North Africa, the Middle East, and Asia. IUCN Global Survey and Regional Action Plan, Gland, Switzerland.

Fisher, M. \& D.A. Membery (1998). Climate, pp. 5-38. In: Ghazanfar, S.A. \& M. Fisher (eds.). Vegetation of the Arabian Peninsula. Kluwer Academic Publishers, Dordrecht.

Flammand, J.R.B., C.R. Thouless, H. Tatwany \& J.F. Asmodé (1998). Status of the gazelles of the Farasan Islands, Saudi Arabia. Mammalia 52(4): 608-610; http://dx.doi.org/10.1515/mamm-1988-0422

Green, A A. (1986). Status of large mammals in northern Saudi Arabia. Mammalia 50(4): 483-493; http://dx.doi.org/10.1515/ mamm.1986.50.4.483

Greth, A., C. Magin \& M. Ancrenaz (eds.) (1996). Conservation of Arabian Gazelles. Proceedings of the Symposium "Establishing Priorities for Gazelle Conservation in the Arabian Peninsula", held at the National Commission for Wildlife Conservation and Development (NCWCD) in Riyadh, Saudi Arabia, 31 October - 03 November 1992, 168pp.

Groves, C.P. (1997). Taxonomy of Arabian Gazelles, pp. 24-51. In Habibi, K., A. Abu-Zinada \& I.A. Nader (eds.). The Gazelles of Arabia. National Commission for Wildlife Conservation and Development, Riyadh.

Grubb, P. (2005). Artiodactyla, pp. 637-722. In: Wilson, D.E. \& D.M. Reeder (eds.). Mammal Species of the World. A Taxonomic and
Geographic Reference (3rd Edition). Johns Hopkins University Press, Baltimore, USA

Habibi, K. (1986). Arabian ungulates: their status and future protection. Oryx 20: 100-103.

Habibi, K. (1992). Arabian Gazelles. National Commission for Wildlife Conservation and Development. Publication No. 4, Riayadh.

Harrison, D.L. (1968). Mammals of Arabia - Volume 2. Ernest Benn, London.

Hammond, R.L., W. Macasero, B. Flores, O.B. Mohammed, T. Wacher \& M. Bruford (2001). Phylogenetic reanalysis of the Saudi Gazelle and its implications for conservation. Conservation Biology 15(4): 1123-1133; http://dx.doi.org/10.1046/j.15231739.2001.0150041123.x

Insall, D.H. (2001). Oman, pp. 69-73. In: Mallon, D.P. \& S.C. Kingswood (eds.). Antelopes. Part 4: North Africa, the Middle East, and Asia. Global Survey and Regional Action Plans. IUCN, Gland, Switzerland.

Islam, M.Z., C. Knutson \& A. Boug (2010b). Strategy and Action Plan to Reduce the Risk of Mass Mortalities of Reintroduced ungulates in the Mahazat as-Sayd Protected Area in Saudi Arabia. GNUSLETTER (IUCN) 28(2): 9-15.

Islam, M.Z., K. Ismail \& A. Boug (2010a). Catastrophic die-off of globally threatened Arabian Oryx and Sand Gazelle in the fenced protected area of the arid central Saudi Arabia. Journal of Threatened Taxa 2(2): 677-684; http://dx.doi.org/10.11609/JoTT.o2174.677-84

Islam, Z.M., T. Wacher, A. Boug \& T. Wronski (2012). Population development of re-introduced Mountain Gazelle in the western Empty Quarter (Uruq Bani Ma'arid Protected Area), Saudi Arabia, pp. 180-184. In: Soorae, P.S. (ed.). Global re-introduction perspectives: 2011. Additional case studies from around the globe. IUCN/SSC Re-introduction Specialist Group (RSG), Abu Dhabi, UAE. IUCN Red List (2014). http://www.iucnredlist.org

IUCN/SSC ASG (2009). Quarter of antelope species in danger of extinction. IUCN Red List of Threatened Species. Gnusletter 28(1): 2-5.

IUCN (1998). IUCN/SSC Guidelines For Re-Introductions. Prepared by the SSC Re-introduction Specialist Group. IUCN Council, Gland Switzerland.

Kankılıç, T., D. Özüt, ş. Gürler, M. Kence, F. Bozkaya \& A. Kence (2012). Rediscovery of a new mountain gazelle population and clarification of taxonomic status of the genus Gazella in Turkey using mtDNA sequencing. Folia Zoologica 61(2): 129-137.

Kingswood, S.C. \& N.H. Khairallah (2001). Lebanon, pp. 99-101. In: Mallon, D.P. \& S.C. Kingswood (eds.). Antelopes. Part 4: North Africa, the Middle East, and Asia. Global Survey and Regional Action Plans. IUCN, Gland, Switzerland.

Lerp, H., T. Wronski, M. Plath, A. Schröter \& M. Pfenninger (2013). Phylogenetic and population genetic analyses confirm the existence of a distinct species boundary between Mountain (Gazella gazella) and Arabian Gazelles (G. arabica) in the Levant. Mammalian Biology 78: 220-225.

Magin, C. (1993). Survey of gazelle species in the south-west of Saudi Arabia. Unpublished Report, King Khalid Wildlife Research Centre, Thumamah, Saudi Arabia.

Magin, C. (1996). Survey of gazelle populations in south-west Saudi Arabia and recommendations for their conservation, pp. 138-148. In: Greth, A., C. Magin \& M. Ancrenaz (eds.). Conservation of Arabian Gazelles. National Commission for Wildlife Conservation and Development, Riyadh, Saudi Arabia.

Magin, C.D. \& A. Greth (1994). Distribution, status and proposals for the conservation of Mountain Gazelles Gazella gazella cora in the southwest of Saudi Arabia. Biological Conservation 70(1): 69-75; http://dx.doi.org/10.1016/0006-3207(94)90300-X

Mallon, D.P. \& M. Al-Safadi (2001). Saudi Arabia, pp. 63-68. In: Mallon, D.P. \& S.C. Kingswood (eds.). Antelopes, Part 4: North Africa, the Middle East, and Asia. IUCN Global Survey and Regional Action Plans, Gland, Switzerland.

Mallon, D.P. \& S.C. Kingswood (2001). Antelopes. Part 4: North Africa, the Middle East, and Asia. Global Survey and Regional Action Plans. IUCN, Gland, Switzerland. 
Masseti, M. (2004). Artiodactyls of Syria. Zoology in the Middle East 33(1): 139-148; http://dx.doi.org/10.1080/09397140.2004.10638 072

Nader, I.A. (1989). Rare and endangered mammals of Saudi Arabia. In: Abu-Zinada, A.H., P.D. Goriup \& I.A. Nader (eds.). Wildlife conservation and development in Saudi Arabia. Proceedings of the First Symposium, Riayadh 1987. National Commission for Wildlife Conservation and Development (NCWCD), Publication No. 3, Riayadh.

Ostrowski, S. \& J.B. Williams (2006). Heterothermy of free-living Arabian sand gazelles (Gazella subgutturosa marica) in a desert environment. Journal of Experimental Biology 209: 1421-1429; http://dx.doi.org/10.1242/jeb.02151

Saleh, M.A. (2001). Chapter 7. Egypt, pp. 48-54. In: Mallon, D.P. \& S.C. Kingswood (eds.). Global Survey and Regional Action Plans: Antelopes. Part 4: North Africa, the Middle East, and Asia. IUCN, Gland, Switzerland.

Samour, J.H. (2001). United Arab Emirates, pp. 74-78. In: Mallon, D.P. \& S.C. Kingswood (eds.). Antelopes, Part 4: North Africa, the Middle East, and Asia. IUCN Global Survey and Regional Action Plans, Gland, Switzerland.

Seddon, P.J., Y. van Heezik \& I.A. Nader (1997). Mammals of the Harrat al-Harrah protected area, Saudi Arabia. Zoology in the Middle East 14(1): 37-46; http://dx.doi.org/10.1080/09397140.19 97.10637702

Shah, M.S., M.Z. Islam \& A. Boug (2013). Re-introduction of Arabian Gazelles (Gazella arabica) in fenced Protected Area in central Saud Arabia. IUCN Re-introduction book, 174-179pp.

Shalmon, B. (1987). The Arava gazelle. Israel - Land and Nature 13: $15-18$.

Thouless, C.R. \& K. Al Bassri (1991). Taxonomic status of the Farasan Island gazelle. Journal of Zoology (London) 223(1): 151-159; http:// dx.doi.org/10.1111/j.1469-7998.1991.tb04756.x

Thouless, C.R., J. Grainger, M. Shobrak \& K. Habibi (1991). Conservation status of gazelles in Saudi Arabia. Biological Conservation 58: 85-98; http://dx.doi.org/10.1016/0006-3207(91)90046-C

Thouless, C.R., K. Habibi, C. Magin \& T.J. Wacher (1997). Status and distribution of gazelles in Saudi Arabia, pp. 52-67. In: Habibi, K., A.H. Abuzinada \& I.A. Nader (eds.). The Gazelles of Arabia. Nationa Commission for Wildlife Conservation and Development, Riyadh, Saudi Arabia.

Treydte, A.C., J.B. Williams, E. Bedin, S. Ostrowski, P.J. Seddon, E.A. Marschall, T.A. Waite \& K. Ismail (2001). In search of the optimal management strategy of Arabian Oryx in Mahazat as-Sayd, Saudi Arabia. Animal Conservation 4(3): 239-249; http://dx.doi. org/10.1017/S1367943001001287

Uerpmann, H.P. (1987). The ancient distribution of ungulate mammals in the Middle East. Beiheft zum Tübinger Atlas des Vorderen Orients. Reihe A (Naturwissenschaften) Nr. 27. Ludwig Reichert Verlag. Wiesbaden 1987.

Vassey-Fitgerald, L.D.E.F. (1952). Wildlife in Arabia. Oryx 1: 232-235.

Wacher, T.J. (1993). Gazelle and camel surveys: Harrat Al Harrah and Al Khunfah Protected Areas, Saudi Arabia. Unpublished Report, King Khalid Wildlife Research Centre, Thumamah, Saudi Arabia.

Wacher, T.J. (2001). Harrat Uwayrid gazelle survey. Unpublished Report, King Khalid Wildlife Research Centre, Thumamah, Saudi Arabia.

Wacher, T.J. \& K. Alageel (1999). Gazelle survey: the Gulf of Aqaba between Maqna and Haqil. Unpublished Report, King Khalid Wildlife Research Centre, Thumamah, Saudi Arabia.

Wacher, T.J. \& K. Alageel (2001a). Gazelle survey: Makshush \& Al Hayla. Unpublished Report, King Khalid Wildlife Research Centre, Thumamah, Saudi Arabia.

Wacher, T.J. \& K. Alageel (2001b). Reconnaissance survey of Jabal Shada. Unpublished Report, King Khalid Wildlife Research Centre, Thumamah, Saudi Arabia.

Wacher, T.J. \& M. Al Toum (1998). Gazelle survey: visit to Wadi Shirs near Tibalah. Unpublished Report, King Khalid Wildlife Research Centre, Thumamah, Saudi Arabia.

Wacher, T.J. \& M. Strauss (2000). Field survey: Ra's Suwaihil and Gulf of Aqaba. Unpublished Report, King Khalid Wildlife Research Centre, Thumamah, Saudi Arabia.

Wronski, T., M.Z. Islam \& M. Plath (2012a). Latrine surveys as a method to estimate the population size of Mountain Gazelle (Gazella arabica). Mammalian Biology 78(3): 226-230; http:// dx.doi.org/10.1016/j.mambio.2012.07.158

Wronski, T., K. Alageel, M. Plath \& M.A. Sandouka (2012b). Twenty years monitoring re-introduced Mountain Gazelles in the Ibex Reserve, Saudi Arabia. Zoology in the Middle East 55: 3-18.

Wronski, T., M.A. Sandouka \& T.M. Butynski (2012c). Twenty years conservation and monitoring of re-introduced Mountain Gazelle in the Ibex Reserve, Saudi Arabia, pp. 175-179. In: Soorae, P.S. (ed.). Global re-introduction perspectives: 2011. Additional case studies from around the globe. IUCN/SSC Re-introduction Specialist Group (RSG), Abu Dhabi, UAE. 